\title{
The M-Homomorphism and M-Anti Homomorphism of an M-Fuzzy Subgroup and its Level M-Subgroups
}

\author{
R.Muthuraj \\ Department of Mathematics \\ PSNA CET, Dindigul. - 624622
}

\author{
M.Rajinikannan \\ Department of MCA \\ PSNA CET, Dindigul. - 624622
}

\author{
M.S.Muthuraman \\ Department of Mathematics \\ PSNA CET, Dindigul. - 624622
}

\begin{abstract}
In this paper, we introduce the concept of an M-fuzzy subgroup

of an M-group and discussed some of its properties.

2000 Mathematics Subject Classification: 22F05, 06F10.

\section{Keywords}

M-group, fuzzy set, fuzzy subgroup, M-fuzzy subgroup of an Mgroup, level subset, level M-subgroups , M-homomorphism , M-anti homomorphism.
\end{abstract}

\section{Introduction}

The concept of fuzzy sets was initiated by Zadeh. Then it has become a vigorous area of research in engineering, medical science, social science, graph theory etc. Rosenfeld gave the idea of fuzzy subgroups. Author N. Jacobson introduced the concept of M-group, M-subgroup.

\section{Preliminaries}

This section contains some definitions and results to be used in the sequel.

\subsection{Definition}

Let $\mathrm{S}$ be a set. A fuzzy subset $\mathrm{A}$ of $\mathrm{S}$ is a function $\mathrm{A}: \mathrm{S} \rightarrow[0,1]$.

\subsection{Definition}

Let $\mathrm{G}$ be a group. A fuzzy subset $\mathrm{A}$ of $\mathrm{G}$ is called a fuzzy subgroup if for $\mathrm{x}, \mathrm{y} \in \mathrm{G}$,

$$
\mathrm{A}(\mathrm{xy}) \geq \min \{\mathrm{A}(\mathrm{x}), \mathrm{A}(\mathrm{y})\},
$$$$
\text { (ii) } \quad \mathrm{A}\left(\mathrm{x}^{-1}\right)=\mathrm{A}(\mathrm{x}) \text {. }
$$

\subsection{Definition}

A group with operators is an algebraic system consisting of a group $\mathrm{G}$, a set $\mathrm{M}$ and a function defined in the product set $\mathrm{M} \times$ $\mathrm{G}$ and having values in $\mathrm{G}$ such that, if ma denotes the element in $\mathrm{G}$ determined by the element a of $\mathrm{G}$ and the element $\mathrm{m}$ of $\mathrm{M}$, then $\mathrm{m}(\mathrm{ab})=(\mathrm{ma})(\mathrm{mb})$ holds for all $\mathrm{a}, \mathrm{b} \in \mathrm{G}$ and $\mathrm{m} \in \mathrm{M}$. We shall use the phrases " $\mathrm{G}$ is an M-group" to a group with operators.

A subgroup $\mathrm{H}$ of an $\mathrm{M}$-group $\mathrm{G}$ is said to be an $\mathrm{M}$ subgroup if $\mathrm{mx} \in \mathrm{H}$ for all $\mathrm{m} \in \mathrm{M}$ and $\mathrm{x} \in \mathrm{H}$.

\subsection{Definition}

Let $\mathrm{G}$ be an M-group and $\mathrm{A}$ be a fuzzy subgroup of $\mathrm{G}$ . Then A is called an M-fuzzy subgroup of $G$ if for all $x \in G$ and $\mathrm{m} \in \mathrm{M}$, then $\mathrm{A}(\mathrm{mx}) \quad \geq \mathrm{A}(\mathrm{x})$.

\subsection{Definition}

Let $\mathrm{A}$ be a fuzzy subset of $\mathrm{S}$. For $\mathrm{t} \in[0,1]$, the level subset of $A$ is the set, $A_{t}=\{x \in S: A(x) \geq t\}$.

\subsection{Definition}

Let $\mathrm{G}$ be a finite group of order $\mathrm{n}$ and $\mathrm{A}$ be a fuzzy subgroup of $G$. Let $\operatorname{Im}(A)=\left\{t_{i}: A(x)=t_{i}\right.$ for some $\left.x \in G\right\}$. Then $\left\{A_{t i}\right\}$ are the only level subgroups of A.

\subsection{Example}

Let A be a fuzzy subset of an M-group G, then A is defined by

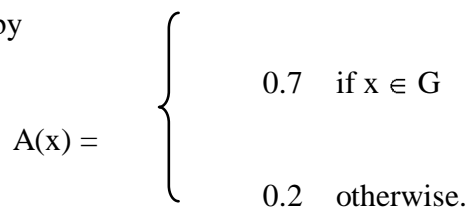

Then it is easy to verify that A is an M-fuzzy subgroup of G.

\subsection{Definition}

Let $\mathrm{G}$ and $\mathrm{G}^{\prime}$ be any two M-groups. Then the function $f: G \rightarrow G^{\prime}$ is said to be an M-homomorphism if

(i) $\quad f(x y)=f(x) f(y)$ for all $x, y$ in $G$.

(ii) $\quad f(m x)=m f(x)$ for all $m$ in $M$ and $x$ in $G$.

\subsection{Definition}


Let $\mathrm{G}$ and $\mathrm{G}^{\prime}$ be any two M-groups (not necessarily commutative). Then the function $\quad f: G \rightarrow G^{\prime}$ is said to be an M-anti homomorphism if

(i) $\quad f(x y)=f(y) f(x)$ for all $x, y \in G$.

(ii) $\quad \mathrm{f}(\mathrm{mx})=\mathrm{m} f(\mathrm{x})$ for all $\mathrm{m}$ in $\mathrm{M}$ and $\mathrm{x}$ in $\mathrm{G}$.

\section{M-fuzzy subgroups of an M-group G under}

\section{M-homomorphism and M-anti homomorphism}

\subsection{Theorem}

Let $\mathrm{f}$ be a M-homomorphism from an M-group $\mathrm{G}$ onto an M-group $\mathrm{G}^{\prime}$. If $\mathrm{A}$ is an M- fuzzy subgroup of $\mathrm{G}$ and $\mathrm{A}$ is $\mathrm{f}$ invariant, then $\mathrm{f}(\mathrm{A})$, the image of $\mathrm{A}$ under $\mathrm{f}$, is an

M- fuzzy subgroup of $\mathrm{G}^{\prime}$.

Proof

$$
\text { Let } \alpha \in \operatorname{Image} \mathrm{f}(\mathrm{A}) \text {. }
$$

Then for some $\mathrm{y} \in \mathrm{G}^{\prime},(\mathrm{f}(\mathrm{A}))(\mathrm{y})=\sup _{\mathrm{x} \in \mathrm{f}^{-1}(\mathrm{y})} \mathrm{A}(\mathrm{x})=\alpha$, where $\alpha \leq \mathrm{A}(\mathrm{e})$.

Clearly $\mathrm{A}_{\alpha}$ is an M-subgroup of $\mathrm{G}$.

If $\alpha=1$, then $(\mathrm{f}(\mathrm{A}))_{\alpha}=\mathrm{G}^{\prime}$.

If $0<\alpha<1$, then ( $\mathrm{f}(\mathrm{A}))_{\alpha}=\mathrm{f}\left(\mathrm{A}_{\alpha}\right)$, because,

$$
\begin{aligned}
\mathrm{z} \in(\mathrm{f}(\mathrm{A}))_{\alpha} \Leftrightarrow & (\mathrm{f}(\mathrm{A}))(\mathrm{z}) \geq \alpha . \\
\Leftrightarrow & \sup _{\mathrm{x} \in \mathrm{f}^{-1}(\mathrm{z})} \mathrm{A}(\mathrm{x}) \geq \alpha .(\text { since } 0<\alpha<1) \\
\Leftrightarrow & \text { there exists } \mathrm{x} \text { in } \mathrm{G} \text { such that } \mathrm{f}(\mathrm{x})=\mathrm{z} \\
& \text { and } \mathrm{A}(\mathrm{x}) \geq \alpha . \\
\Leftrightarrow & \mathrm{z} \in\left(\mathrm{f}\left(\mathrm{A}_{\alpha}\right)\right) .
\end{aligned}
$$

Hence, $(\mathrm{f}(\mathrm{A}))_{\alpha}=\left(\mathrm{f}\left(\mathrm{A}_{\alpha}\right)\right)$.

Since $\mathrm{f}$ is an M-homomorphism, $\left(\mathrm{f}\left(\mathrm{A}_{\alpha}\right)\right)$ is an M-subgroup of $\mathrm{G}^{\prime}$.

Hence $(\mathrm{f}(\mathrm{A}))_{\alpha}$ is an M-subgroup of $\mathrm{G}^{\prime}$.

Hence $\mathrm{f}(\mathrm{A})$ is an M- fuzzy subgroup of $\mathrm{G}^{\prime}$.

\subsection{Theorem}

The M-homomorphic pre-image of an M-fuzzy subgroup of an M-group $\mathrm{G}^{\prime}$ is an M-fuzzy subgroup of an Mgroup $\mathrm{G}$.

Proof
Let $\mathrm{f}: \mathrm{G} \rightarrow \mathrm{G}^{\prime}$ be an M-homomorphism. Let the fuzzy set $\mathrm{V}$ on $\mathrm{G}^{\prime}$ be an $\mathrm{M}$-fuzzy subgroup.

We have to prove that any fuzzy set $A$ on $G$ is an M-fuzzy subgroup, where $V=f(A)$.

Now

$$
\begin{aligned}
A(x y) & =V(f(x y)) \\
& =V(f(x) f(y)) \quad \text { as } f \text { is an M-homomorphism. } \\
& \geq \min \{V(f(x)), V(f(y))\}
\end{aligned}
$$$$
\text { as } \mathrm{V} \text { is an M-fuzzy subgroup of } \mathrm{G}^{\prime} \text {. }
$$$$
=\min \{\mathrm{A}(\mathrm{x}), \mathrm{A}(\mathrm{y})\} \text {. }
$$

That is, $A(x y) \geq \min \{A(x), A(y)\}$.

For $\mathrm{x} \in \mathrm{G}$,

$$
\begin{aligned}
\mathrm{A}\left(\mathrm{x}^{-1}\right) & =\mathrm{V}\left(\mathrm{f}\left(\mathrm{x}^{-1}\right)\right) \\
& =\mathrm{V}\left(\left(\mathrm{f}(\mathrm{x})^{-1}\right)\right) \quad \text { as } \mathrm{f} \text { is an M-homomorphism } \\
& =\mathrm{V}(\mathrm{f}(\mathrm{x})) \text { as } \mathrm{V} \text { is an M-fuzzy subgroup of } \mathrm{G}^{\prime} \\
& =\mathrm{A}(\mathrm{x}) .
\end{aligned}
$$

That is, $\mathrm{A}\left(\mathrm{x}^{-1}\right)=\mathrm{A}(\mathrm{x})$.

Clearly, $\mathrm{A}(\mathrm{mx}) \quad=\mathrm{V}(\mathrm{f}(\mathrm{mx}))$

$=\mathrm{V}(\mathrm{mf}(\mathrm{x})), \quad$ as $\mathrm{f}$ is an M-homomorphism

$\geq \mathrm{V}(\mathrm{f}(\mathrm{x}))$ as $\mathrm{V}$ is an M-fuzzy subgroup of $\mathrm{G}^{\prime}$

$=\mathrm{A}(\mathrm{x})$.

That is, $\mathrm{A}(\mathrm{mx}) \quad \geq \mathrm{A}(\mathrm{x})$.

Hence A is an M-fuzzy subgroup of G.

\subsection{Theorem}

Let $\mathrm{f}$ be an $\mathrm{M}$-anti homomorphism from an M-group $\mathrm{G}$ onto an M-group $\mathrm{G}^{\prime}$. If $\mathrm{A}$ is an M- fuzzy subgroup of $\mathrm{G}$ and $\mathrm{A}$ is $\mathrm{f}$-invariant, then $\mathrm{f}(\mathrm{A})$, the image of $\mathrm{A}$ under $\mathrm{f}$, is an $\mathrm{M}$ fuzzy subgroup of $\mathrm{G}^{\prime}$.

Proof

$$
\text { Let } \alpha \in \text { Image } \mathrm{f}(\mathrm{A}) \text {. }
$$

Then for some $\mathrm{y} \in \mathrm{G}^{\prime},(\mathrm{f}(\mathrm{A}))(\mathrm{y})=\sup _{\mathrm{x} \in \mathrm{f}^{-1}(\mathrm{y})} \mathrm{A}(\mathrm{x})=\alpha$, where $\alpha \leq \mathrm{A}(\mathrm{e})$.

Clearly $\mathrm{A}_{\alpha}$ is an M-subgroup of $\mathrm{G}$.

If $\alpha=1$, then $(\mathrm{f}(\mathrm{A}))_{\alpha}=\mathrm{G}^{\prime}$.

$$
\begin{aligned}
& \text { If } 0<\alpha<1 \text {, then (f(A) })_{\alpha}=\mathrm{f}\left(\mathrm{A}_{\alpha}\right) \text {, because } \\
& \qquad \begin{aligned}
\mathrm{z} \in(\mathrm{f}(\mathrm{A}))_{\alpha} & \Leftrightarrow(\mathrm{f}(\mathrm{A}))(\mathrm{z}) \geq \alpha . \\
& \Leftrightarrow \sup \mathrm{A}(\mathrm{x}) \geq \alpha \cdot(\text { since } 0<\alpha<1) \\
& \quad \Leftrightarrow \quad \text { there exists } \mathrm{x} \text { in } \mathrm{f} \text { such that } \mathrm{f}(\mathrm{x})=\mathrm{z}
\end{aligned}
\end{aligned}
$$




$$
\begin{aligned}
& \quad \text { and } \quad A(x) \geq \alpha \text {. } \\
& \Leftrightarrow \mathrm{z} \in\left(\mathrm{f}\left(\mathrm{A}_{\alpha}\right)\right) .
\end{aligned}
$$

Hence, $(\mathrm{f}(\mathrm{A}))_{\alpha}=\left(\mathrm{f}\left(\mathrm{A}_{\alpha}\right)\right)$.

Since $\mathrm{f}$ is an M- anti homomorphism, $\left(\mathrm{f}\left(\mathrm{A}_{\alpha}\right)\right)$ is an M-subgroup of $\mathrm{G}^{\prime}$.

Hence $(\mathrm{f}(\mathrm{A}))_{\alpha}$ is an M-subgroup of $\mathrm{G}^{\prime}$.

Hence $\mathrm{f}(\mathrm{A})$ is an M- fuzzy subgroup of $\mathrm{G}^{\prime}$.

\subsection{Theorem}

The M-anti homomorphic pre-image of an M-fuzzy subgroup of an M-group $\mathrm{G}^{\prime}$ is an M-fuzzy subgroup of an Mgroup $\mathrm{G}$.

Proof

Let $\mathrm{f}: \mathrm{G} \rightarrow \mathrm{G}^{\prime}$ be an M-anti homomorphism. Let the fuzzy set $\mathrm{V}$ on $\mathrm{G}^{\prime}$ be an M-fuzzy subgroup.

We have to prove that any fuzzy set A on $G$ is an M-fuzzy subgroup, where $\mathrm{V}=\mathrm{f}(\mathrm{A})$.

$$
\begin{aligned}
\text { Now, } A(x y)= & V(f(x y)) . \\
= & V(f(x) f(y)) \\
& \text { as } f \text { is an M-anti homomorphism. } \\
\geq & \min \{\mathrm{V}(\mathrm{f}(\mathrm{x})), \mathrm{V}(\mathrm{f}(\mathrm{y}))\} \\
& \text { as } \mathrm{V} \text { is an M- fuzzy subgroup of } \mathrm{G}^{\prime} . \\
= & \min \{\mathrm{A}(\mathrm{x}), \mathrm{A}(\mathrm{y})\} . \\
\text { That is, } \mathrm{A}(\mathrm{xy}) \quad & \min \{\mathrm{A}(\mathrm{x}), \mathrm{A}(\mathrm{y})\} . \\
\text { For } \mathrm{x} \in \mathrm{G}, \quad \mathrm{A}\left(\mathrm{x}^{-1}\right)= & \mathrm{V}\left(\mathrm{f}\left(\mathrm{x}^{-1}\right)\right) \\
= & \mathrm{V}\left(\left(\mathrm{f}(\mathrm{x})^{-1}\right)\right) \text { as } \mathrm{f} \text { is an M-anti homomorphism } \\
= & \mathrm{V}(\mathrm{f}(\mathrm{x})) \text { as } \mathrm{V} \text { is an M-fuzzy subgroup of } \mathrm{G}^{\prime} \\
= & \mathrm{A}(\mathrm{x}) .
\end{aligned}
$$

That is, $\mathrm{A}\left(\mathrm{x}^{-1}\right)=\mathrm{A}(\mathrm{x})$.

Clearly, $\mathrm{A}(\mathrm{mx}) \quad=\mathrm{V}(\mathrm{f}(\mathrm{mx}))$

$=\mathrm{V}(\operatorname{mf}(\mathrm{x}))$, as $\mathrm{f}$ is an M-anti homomorphism $\geq \mathrm{V}(\mathrm{f}(\mathrm{x}))$ as $\mathrm{V}$ is an M-fuzzy subgroup of $\mathrm{G}^{\prime}$

$$
=\mathrm{A}(\mathrm{x}) \text {. }
$$

That is, $\mathrm{A}(\mathrm{mx}) \quad \geq \mathrm{A}(\mathrm{x})$.

Hence $\mathrm{A}$ is an M-fuzzy subgroup of G.

\section{Properties of level subsets of an M-fuzzy subgroup of an M-group:}

\subsection{Theorem}

Let $\mathrm{A}$ be a fuzzy subset of an M-group G. If $\mathrm{A}$ is an Mfuzzy subgroup of $G$, then the level subsets $A_{t}, t \in \operatorname{Im}(A)$ are M-subgroups of $\mathrm{G}$.

Proof

Let $\mathrm{t} \in \operatorname{Im}(\mathrm{A})$ and $\mathrm{x}, \mathrm{y} \in \mathrm{A}_{\mathrm{t}}$.

Then $\mathrm{A}(\mathrm{x})=\mathrm{t}$ and $\mathrm{A}(\mathrm{y})=\mathrm{t}$.

Given that A is an M-fuzzy subgroup of G.

Therefore, $\mathrm{A}$ is a fuzzy subgroup of $\mathrm{G}$.

Hence $\mathrm{A}(\mathrm{xy}) \geq \min \{\mathrm{A}(\mathrm{x}), \mathrm{A}(\mathrm{y})\}=\mathrm{t}$.

That is, $\mathrm{A}(\mathrm{xy}) \geq \mathrm{t}$.

That is, $x y \in A_{t}$.

Moreover, if $\mathrm{x} \in \mathrm{A}_{\mathrm{t}}$, then $\mathrm{A}\left(\mathrm{x}^{-1}\right)=\mathrm{A}(\mathrm{x}) \geq \mathrm{t}$.

Hence $x^{-1} \in A_{t}$.

Hence $A_{t}$ is a subgroup of $G$.

Now, for any $x \in A_{t}$ and $m \in M$, then

$\mathrm{A}(\mathrm{mx}) \geq \mathrm{A}(\mathrm{x}) \geq \mathrm{t}$.

Hence $m x \in A_{t}$.

Hence $A_{t}$ is an M-subgroup of $G$.

\subsection{Theorem}

Let A be a fuzzy subset of an M-group G. If the level subsets $A_{t}, t \in \operatorname{Im}(A)$ are $M$-subgroups of $G$, then $A$ is an $M$ fuzzy subgroup of $\mathrm{G}$.

\section{Proof}

Let the level subsets $A_{t}, t \in \operatorname{Im}(A)$ are M-subgroups of $G$.

If there exist $\mathrm{x}_{0}, \mathrm{y}_{0} \in \mathrm{G}$ such that $\mathrm{A}\left(\mathrm{x}_{0} \mathrm{y}_{0}\right)<\min \left\{\mathrm{A}\left(\mathrm{x}_{0}\right), \mathrm{A}\left(\mathrm{y}_{0}\right)\right\}$.

Let $\mathrm{t}_{0}=\left(\mathrm{A}\left(\mathrm{x}_{0} \mathrm{y}_{0}\right)+\min \left\{\mathrm{A}\left(\mathrm{x}_{0}\right), \mathrm{A}\left(\mathrm{y}_{0}\right)\right\}\right) / 2$, we have $\mathrm{A}\left(\mathrm{x}_{0} \mathrm{y}_{0}\right)<\mathrm{t}_{0}$ $<\min \left\{\mathrm{A}\left(\mathrm{x}_{0}\right), \mathrm{A}\left(\mathrm{y}_{0}\right)\right\}$.

It follows that $\mathrm{x}_{0}, \mathrm{y}_{0} \in \mathrm{A}_{\mathrm{t} 0}$, but $\mathrm{x}_{0} \mathrm{y}_{0} \notin \mathrm{A}_{\mathrm{t} 0}$.

Which is a contradiction.

Hence $\mathrm{A}(\mathrm{xy}) \geq \min \{\mathrm{A}(\mathrm{x}), \mathrm{A}(\mathrm{y})\}$.

Similarly, we have $\mathrm{A}\left(\mathrm{x}^{-1}\right) \geq \mathrm{A}(\mathrm{x})$.

Hence $\mathrm{A}$ is a fuzzy subgroup of $\mathrm{G}$.

Now, suppose, for $\mathrm{m} \in \mathrm{M}$ and $\mathrm{x} \in \mathrm{G}, \mathrm{A}(\mathrm{mx})<\mathrm{A}(\mathrm{x})$.

Let $\mathrm{t}_{0}=(\mathrm{A}(\mathrm{mx})+\mathrm{A}(\mathrm{x})) / 2$.

Then, $\mathrm{A}(\mathrm{mx})<\mathrm{t}_{0}<\mathrm{A}(\mathrm{x})$.

That is , for $m \in M$ and $x \in G$, then $x \in A_{t 0}$, but $m x \notin A_{t 0}$.

Which is a contradiction to $\mathrm{A}_{\mathrm{t} 0}$ is a M-subgroup of $\mathrm{G}$.

Hence $\mathrm{A}(\mathrm{mx}) \geq \mathrm{A}(\mathrm{x})$.

Hence $\mathrm{A}$ is an M-fuzzy subgroup of $\mathrm{G}$.

\subsection{Definition}


Let A be an M- fuzzy subgroup of an M-group G. Then the M-subgroups $A_{t}$, for $t \in[0,1]$ and $t \geq A(e)$, are called level M-subgroups of A.

\section{Level M-subgroups of M-fuzzy subgroups of an M-group G under M-homomorphism and M-anti homomorphism \\ 4.1 Theorem}

The M-homomorphic image of a level M-subgroup of an M-fuzzy subgroup A of an M-group G is a level M-subgroup of an M-fuzzy subgroup $f(A)$ of an M-group $G^{\prime}$ where A is finvariant.

\section{Proof}

Let $\mathrm{G}$ and $\mathrm{G}^{\prime}$ be any two M-groups.

Let $\mathrm{f}: \mathrm{G} \rightarrow \mathrm{G}^{\prime}$ be an M-homomorphism.

Let A be an M-fuzzy subgroup of G.

Clearly, $f(A)$ is an M-fuzzy subgroup of $G^{\prime}$.

Let $\mathrm{A}_{\alpha}$ be a level M-subgroup of an M-fuzzy subgroup A of G.

Since $\mathrm{f}$ is an M-homomorphism, $\mathrm{f}\left(\mathrm{A}_{\alpha}\right)$ is an M-subgroup $\mathrm{f}(\mathrm{A})$ of $\mathrm{G}^{\prime}$ and $\mathrm{f}\left(\mathrm{A}_{\alpha}\right)=(\mathrm{f}(\mathrm{A}))_{\alpha}$.

Hence $(\mathrm{f}(\mathrm{A}))_{\alpha}$. is a level M-subgroup $\mathrm{f}(\mathrm{A})$ of $\mathrm{G}^{\prime}$.

\subsection{Theorem}

The M-homomorphic pre-image of a level M-subgroup of an M-fuzzy subgroup $\mathrm{V}$ of an M-group $\mathrm{G}^{\prime}$ is a level Msubgroup of an M-fuzzy subgroup $\mathrm{f}^{-1}(\mathrm{~V})$ of an M-group $\mathrm{G}$.

Proof

Let $\mathrm{G}$ and $\mathrm{G}^{\prime}$ be any two M-groups.

Let $\mathrm{f}: \mathrm{G} \rightarrow \mathrm{G}^{\prime}$ be an M-homomorphism.

Let $\mathrm{V}$ be an M-fuzzy subgroup of $\mathrm{G}^{\prime}$.

Clearly $\mathrm{f}^{-1}(\mathrm{~V})$ is an M-fuzzy subgroup of $\mathrm{G}$.

Let $\mathrm{V}_{\mathrm{t}}$ be a level M-subgroup of an M-fuzzy subgroup $\mathrm{V}$ of $\mathrm{G}^{\prime}$.

Since, $\mathrm{f}$ is an M-homomorphism, $\mathrm{f}^{-1}\left(\mathrm{~V}_{\mathrm{t}}\right)$ is an M-subgroup of $\mathrm{f}^{-1}(\mathrm{~V})$ of $\mathrm{G}$

and $\mathrm{f}^{-1}\left(\mathrm{~V}_{\mathrm{t}}\right)=\left(\mathrm{f}^{-1}(\mathrm{~V})\right)_{\mathrm{t}}$, is an M-subgroup of an M-fuzzy subgroup $\mathrm{f}^{-1}(\mathrm{~V})$ of $\mathrm{G}$.
That is , $\left(\mathrm{f}^{-1}(\mathrm{~V})\right)_{\mathrm{t}}$ is a level M-subgroup of an M-fuzzy subgroup $\mathrm{f}^{-1}(\mathrm{~V})$ of $\mathrm{G}$.

\subsection{Theorem}

The M-anti homomorphic image of a level M-subgroup of an M-fuzzy subgroup A of an M-group $\mathrm{G}$ is a level Msubgroup of an M-fuzzy subgroup $\mathrm{f}(\mathrm{A})$ of an M-group $\mathrm{G}^{\prime}$ where A is f-invariant.

\section{Proof}

Let $\mathrm{G}$ and $\mathrm{G}^{\prime}$ be any two M-groups.

Let $\mathrm{f}: \mathrm{G} \rightarrow \mathrm{G}^{\prime}$ be an M-anti homomorphism.

Let A be an M-fuzzy subgroup of G.

Clearly, $f(A)$ is an M-fuzzy subgroup of $G^{\prime}$.

Let $\mathrm{A}_{\alpha}$ be a level M-subgroup of an M-fuzzy subgroup A of G.

Since $\mathrm{f}$ is an M-anti homomorphism , $\mathrm{f}\left(\mathrm{A}_{\alpha}\right)$ is an M-subgroup $\mathrm{f}(\mathrm{A})$ of $\mathrm{G}^{\prime}$ and $\mathrm{f}\left(\mathrm{A}_{\alpha}\right)=(\mathrm{f}(\mathrm{A}))_{\alpha}$.

Hence $(\mathrm{f}(\mathrm{A}))_{\alpha}$ is a level M-subgroup $\mathrm{f}(\mathrm{A})$ of $\mathrm{G}^{\prime}$.

\subsection{Theorem}

The M-anti homomorphic pre-image of a level Msubgroup of an M-fuzzy subgroup V of an M-group $\mathrm{G}^{\prime}$ is a level M-subgroup of an M-fuzzy subgroup $\mathrm{f}^{-1}(\mathrm{~V})$ of an M-group $\mathrm{G}$.

\section{Proof}

Let $\mathrm{G}$ and $\mathrm{G}^{\prime}$ be any two M-groups.

Let $\mathrm{f}: \mathrm{G} \rightarrow \mathrm{G}^{\prime}$ be an M-anti homomorphism.

Let $\mathrm{V}$ be an M-fuzzy subgroup of $\mathrm{G}^{\prime}$.

Clearly $f^{-1}(V)$ is an M-fuzzy subgroup of $G$.

Let $\mathrm{V}_{\mathrm{t}}$ be a level M-subgroup of an M-fuzzy subgroup $\mathrm{V}$ of $\mathrm{G}^{\prime}$.

Since, $\mathrm{f}$ is an M-anti homomorphism , $\mathrm{f}^{-1}\left(\mathrm{~V}_{\mathrm{t}}\right)$ is an M-subgroup of $\mathrm{f}^{-1}(\mathrm{~V})$ of $\mathrm{G}$

and $\mathrm{f}^{-1}\left(\mathrm{~V}_{\mathrm{t}}\right)=\left(\mathrm{f}^{-1}(\mathrm{~V})\right)_{\mathrm{t}}$, is an M-subgroup of an M-fuzzy subgroup $\mathrm{f}^{-1}(\mathrm{~V})$ of $\mathrm{G}$. 
That is , $\left(\mathrm{f}^{-1}(\mathrm{~V})\right)_{\mathrm{t}}$ is a level M-subgroup of an M-fuzzy subgroup $\mathrm{f}^{-1}(\mathrm{~V})$ of $\mathrm{G}$.

\section{References}

[1] Biswas .R, Fuzzy subgroups and Anti Fuzzy subgroups, Fuzzy sets and Systems, 35(1990) 121-124.

[2] Das. P.S, Fuzzy groups and level subgroups, J.Math.Anal. Appl, 84 (1981) 264-269.
[3] Mohamed Asaad, Groups and Fuzzy subgroups Fuzzy sets and systems 39(1991) 323-328.

[4] Prabir Bhattacharya, Fuzzy Subgroups: Some Characterizations , J.Math. Anal. Appl.128 (1987) 241 - 252.

[5] Rosenfeld, Fuzzy groups, J.Math.Anal.Appl, 35(1971) 512 - 517.

[6] N. Jacobson , Lectures in Abstract Algebra , East - West Press , 1951. 